\title{
Celebrating the 80th Birthday of Professor Zhanpeng Jin
}

Published online: 31 August 2018

(C) ASM International 2018

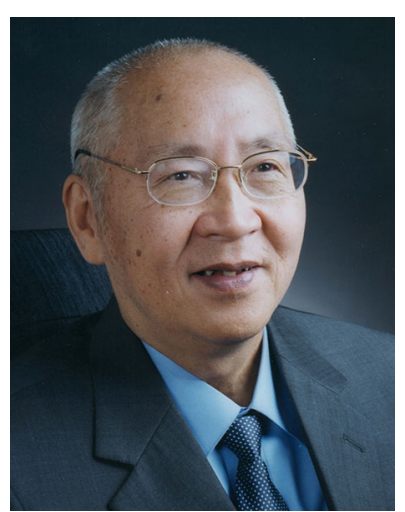

Professor Zhanpeng Jin

The October 2018 issue of the Journal of Phase Equilibria and Diffusion (JPED) is dedicated to the celebration of Professor Zhanpeng Jin's 80th birthday.

Professor Jin is a Professor of Materials Science and Engineering at Central South University (CSU), Changsha, China, where he received both his Bachelor's and Master's degrees in physical metallurgy. From 1978 to 1981, he was a visiting scholar in Professor Mats Hillert's group at the Royal Institute of Technology (KTH) in Stockholm, Sweden. Professor Jin has been teaching and leading research at CSU since he returned from Sweden in 1981. He has trained—and is still training—generations of researchers in phase equilibria, thermodynamic modeling, diffusion, and computational materials design. His students and grandstudents are active around the world, especially in China, Europe, and the United States.

Professor Jin was named one of the ten National Teacher Role Models of China in 2011 for his dedication to education excellence. This prestigious recognition is only awarded to ten teachers-from kindergartens to universities-throughout China each year. As a testament to his dedication, Professor Jin, at the age of 80 , still goes to his CSU office daily, in a wheelchair, to meet his students and grand-students.

The Associate Editors (Zhao and Du) and the Guest Editor (Chen) of this special issue of JPED are all students of Professor Jin. We are thankful to all the authors for accepting our invitation to contribute to this special issue of JPED in honor of Professor Jin. This collection covers a range of topics, from experimental measurement to modeling, from metals to ceramics, from binary systems to high-entropy alloys, from equilibrium to metastability, from phase diagrams to diffusion, and beyond. These topics are all dear to Professor Jin's heart. We plan to hand a copy of this special issue to Professor Jin during his 80th birthday celebration event that is scheduled for November 3 and 4, 2018, at CSU.

\section{Ji-Cheng Zhao}

Associate Editor

Journal of Phase Equilibria and Diffusion

The Ohio State University

Columbus, $\mathrm{OH}$

\section{Yong Du}

Associate Editor

Journal of Phase Equilibria and Diffusion

Central South University

Changsha, China

\section{Qing Chen}

Guest Editor

Journal of Phase Equilibria and Diffusion

Thermo-Calc Software AB

Stockholm, Sweden 